\title{
Technical protection measures against natural hazards taken by the Austrian Federal Service for Torrent, Erosion and Avalanche Control
}

\author{
F. J. Riedl \\ Austrian Federal Service for Torrent, Erosion and Avalanche Control, \\ District Office “Upper Inn Valley”, Austria
}

\begin{abstract}
The focus of the following paper lies in the association between the theory of the planning part and the external practical work, demonstrated on a specific technical protection measure against the torrent "Farstrinne". Experiences during the building period in the year 2008 (damages on the technical mitigation measure caused by two flooding events) led to reconsider the measures undertaken until that time. The daily experience is absolutely necessary to work out protection measures against natural hazards (torrents, avalanches, landslides, rock fall) as well as for further planning works.

Initially, the Austrian Federal Service for Torrent, Erosion and Avalanche Control will be introduced and especially the District Office "Upper Inn Valley". Keywords: Austrian Federal Service for Torrent, Erosion and Avalanche Control, technical protection measures, natural hazards, torrents, avalanches, rock fall, landslides, hazard zone mapping.
\end{abstract}

\section{Introduction}

\subsection{Austrian Federal Service for Torrent, Erosion and Avalanche Control}

The main tasks of the Austrian Federal Service for Torrent, Erosion and Avalanche Control are divided into four category groups:

$>$ hazard zone planning (risk prevention),

$>$ planning of technical mitigation measures against natural hazards,

$>$ building construction of the protection measures and

expertise for the public authorities. 
Therefore, the assignment of the Austrian Federal Service for Torrent, Erosion and Avalanche Control enfolded from risk assessment up to event management in case of extreme events caused by natural disasters.

\section{RISK ANALYSIS}

In the Risk Analysis the definition of the watershed areas, mentioned in the Forestry Law of 1975 [3], monitoring and survey activities in the catchment areas and analysing of hazards and risks are the main parts of our assignments. Furthermore, documenting extreme weather events, collection of the data and management of statistical databases are part of our risk analysis.

\section{RISK ASSESSMENT}

In the Risk Assessment the focus lies within the provision of basic decisionmaking processes. Therefore the hazard zone planning requested in $\S 11$ Forestry Law [3] also maintains the creation of guidelines and regional planning studies. The provision of planning principles and standards are part of the daily work of the Austrian Federal Service for Torrent, Erosion and Avalanche Control.

\section{RISK MANAGEMENT}

After extreme weather events and the treatment of permanent settlements by torrents, avalanches, landslides or rock falls the detailed planning and realisation of protection measures against these natural hazards is essential. In collaboration with the University of Natural Resources and Applied Life Sciences in Vienna, passive protection measures (monitoring and early warning systems) are also be used and installed in specific torrents [8].

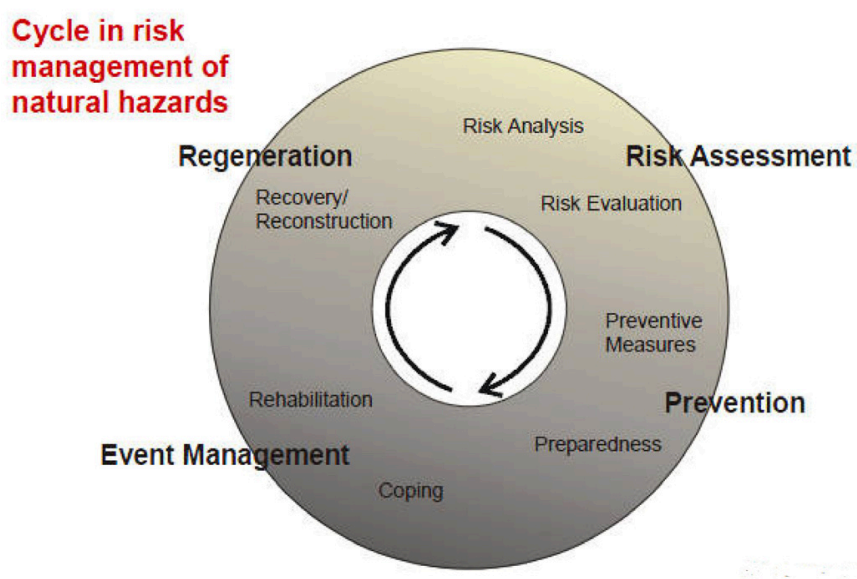

Figure 1: $\quad$ Cycle of risk management after Rickenmann [5]. 


\subsection{District Office "Upper Inn Valley"}

The District Office "Upper Inn Valley", situated in Imst, is responsible for the torrent, avalanche, rock fall and erosion protection in the two mountainous districts Landeck and Imst in the western part of Tyrol. The total area covers $3,320 \mathrm{~km}^{2}$ and the population, scattered in 54 communities, reaches about 96,446 people. The most important source of income of the population of these two districts is tourism. There are annually around 11.1 million overnight stays, $69 \%$ of them being in the winter.

In the Imst and Landeck districts there are about 340 catchment areas (torrents), including 664 harmful avalanche tracks endangering the permanent settlement of space, which is about $7.4 \%$ of the total. Taking the population on the permanent settlement of space, there is a high population density of 391 persons per $\mathrm{km}^{2}$. The described high risk and hazard potential leads to the fact that the District Office "Upper Inn Valley" is one of the most endangered regions of the Alps affected by natural hazards.

The main focus of action lies within the protection against avalanches. Thus, in the last 50 years, extensive construction works (snow supporting structures) were erected. In total about $130 \mathrm{~km}$ snow supporting structures and $500 \mathrm{ha}$ afforestations near the timberline reduce the risk for the permanent settlements.

The District Office "Upper Inn Valley" invests about 9.3 million $€$ annually in protective measures, especially in the construction and planning works [8].

$\begin{array}{ll}61 \% & \text { to protect against avalanches } \\ 24 \% & \text { protection against torrents } \\ 8 \% & \text { in afforestation near the timberline } \\ 7 \% & \text { to protect against rock falls and landslides }\end{array}$

Due to permafrost and the melting of the ice cores in the soil caused by global warming, the rock fall activities have almost doubled in the last 10 years.

\section{Technical protection measure torrent: "Farstrinne", community Umhausen, district Imst}

\subsection{General catchment characteristic of the torrent "Farstrinne"}

The catchment area of the hydrological western drained torrent "Farstrinne" is about $5.5 \mathrm{~km}^{2}$. The highest elevation point in the catchment area is $3010 \mathrm{~m}$ above sea level, which means a difference in height of nearly $2060 \mathrm{~m}$. The upper catchment area is very steep and characterized by numerous gullies. The middle part is mostly rocky with a slope topography of $17-35 \%$. The striking debris cone of the Farstrinne was built up by numerous ancient events, where many blocks of about $4 \mathrm{~m}^{3}$ were deposited. The slope topography of the cone itself is about $20 \%$ and nowadays most of the ground level is used for agricultural work.

From the hydrological point of view, the catchment area belongs to the InnerAlpine, Continental, Climate Zone. The annual precipitation is approximately 
$710 \mathrm{~mm}$ and the previously measured maximal rainfall was $96.1 \mathrm{~mm}$ in 24 hours on 4 Nov. 1966.

The maximum runoff was calculated by the software program ZEMOKOST [4] by monitoring a repeat period of time of 150 years. ZEMOKOST is a recalculated program contemplating the surface runoff und the surface roughness after Markart et al. [2]. For this existing torrent the maximum runoff $\mathrm{HQ}_{150}$ is about $50 \mathrm{~m}^{3}$ per second and the expected bedload deposit considering this maximum runoff, is about $80.000 \mathrm{~m}^{3}$. The bedload deposit was calculated by the empiric formula after Hampel regarding the inclination of the debris cone topography of $20 \%$.

\subsection{Historical information of the torrent "Farstrinne"}

The impressive historical information of damages, caused by the torrent "Farstrinne", leads to the permanent settlement "Östen" situated on the topographical right side of the debris cone. On the one hand this historical information was gained from records taken by the population itself together with the literature of Fliri [1] on the other hand. The smaller events with a repeat period of time of 2-3 years are not mentioned below. These events affect the major road into the Ötztal Valley and leads particularly to an embargo of the main route.

15 July 174980 buildings of the permanent settlement "Östen" were destroyed; 9 persons died.

1760 a debris flow destroyed 20 buildings; no one was injured.

4 July 17628 buildings of "Östen" were buried.

In the years $1767,1791,1807,1830.1854,1855,1857,1862,1874,1878$ and 1891 several debris and hyperconcentrated flows destroyed the church, buildings and agricultural areas of "Östen". The temporary stone construction made by the population itself was completely destroyed and there was no safety anymore.

7 May 1991 A debris flow accounted for about $40.000 \mathrm{~m}^{3}$ manifested itself above and on the major road into the Ötztal Valley as well as between the two temporary protection dams. The torrent broke out on the topographical right side where about 2 ha agricultural areas were affected and destroyed.

In July and August 2008 two events happened during the construction work of the technical mitigation measures. These two events divided into a smaller (July) and a larger one (August) amounted for a total volume of deposit of about $25.000 \mathrm{~m}^{3}$. The protection measures were partly destroyed and the most of the material went down to the downstream deposition basin above the major road. The downstream basin with a capacity of about $15.000 \mathrm{~m}^{3}$ was too small and therefore the major road was closed because of the overwhelming material. 


\subsection{Idea behind the planning and construction works}

Caused by the events up to the year 1991 the District Office "Upper Inn Valley" initiated several technical protection measures on the torrent "Farstrinne". On the upper part of the debris cone a deposition basin with a capacity of about $80.000 \mathrm{~m}^{3}$ was supposed to prevent large destruction. The discharge unit is characterized by a ground fissure of about $2.0 \mathrm{~m}$. The idea behind this construction was that small and middle events are transferred downstream to the already existing second deposition basin. This downstream deposition basin will be enlarged to enable the capacity to reach up to $50.000 \mathrm{~m}^{3}$. The third step in securing the permanent settlement is to expand the existing longitudinal dams where big armourstones should protect the dams against erosion processes.

In the building period of 2008 the main task was to build and complete the upper deposition basin with a deposit capacity of $80.000 \mathrm{~m}^{3}$. The technical details are as follows: $1300 \mathrm{~m}^{3}$ concrete, 60 tonnes steel, $60.000 \mathrm{~m}^{3}$ bulk material and 23.000 tonnes building blocks. The concrete-steel phased discharge unit was planned and realized with an angular steel girder against transported timber during an event, fig. 4. This sorting should ensure a normal runoff of a hyperconcentrated water or debris flow.

The angular steel girder was dimensioned on the base of a 1.5 times hydrostatic normal water pressure. Several ancient deposition basins with a similar discharge unit were constructed and dimensioned in the same way the years before.

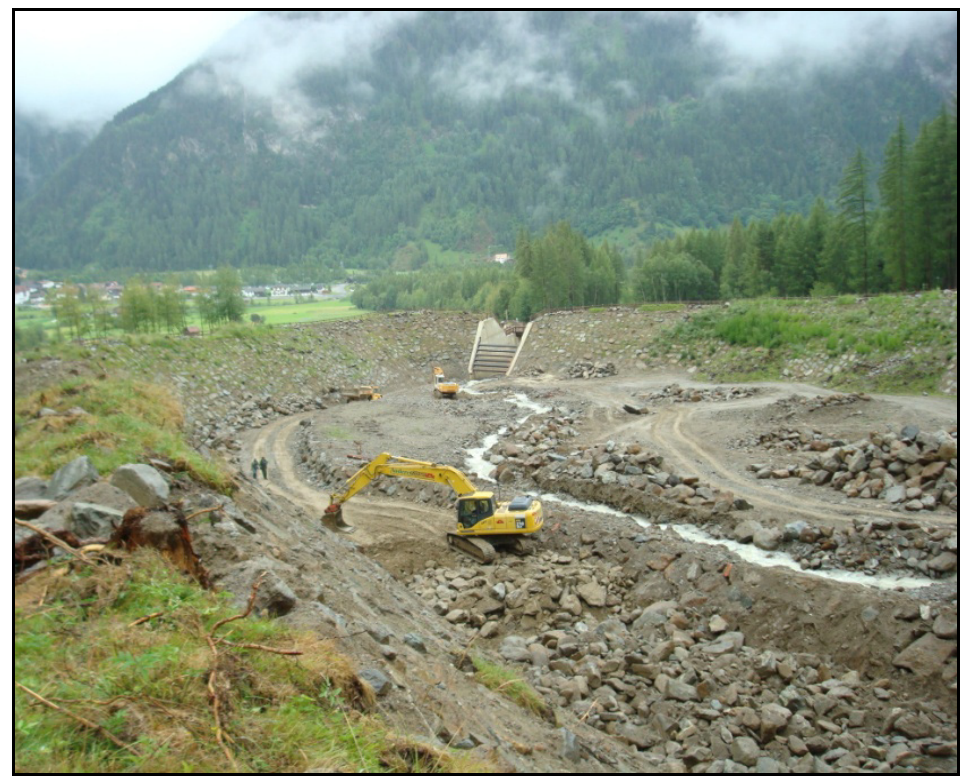

Figure 2: The upper deposition basin with the discharge unit and total deposition capacity up to $80.000 \mathrm{~m}^{3}$. 


\subsection{Hazard zone mapping}

In Austria, hazard zone mapping is mentioned in the Forestry Law of 1975 [2] and in regulations according to the decree of the Ministry for Agriculture and Forestry of 1976. In this decree there are guidelines for hazard mapping and directives for delineation of hazard zones. The delineations are based on specific criteria for torrents and avalanches, fig. 3. The delineations for torrents are based on flow or erosion depths and energy lines of the water. For avalanches, the pressure of the avalanches is essential considering a repeat period of time of 150 years. In the red hazard zone, the installation or construction of buildings is not advised and not allowed. In the yellow hazard zone the construction of buildings are possible and acceptable under certain conditions.

In the present case study of the torrent "Farstrinne" there are about 8 buildings situated in the red hazard zone and 38 buildings in the yellow hazard zone.

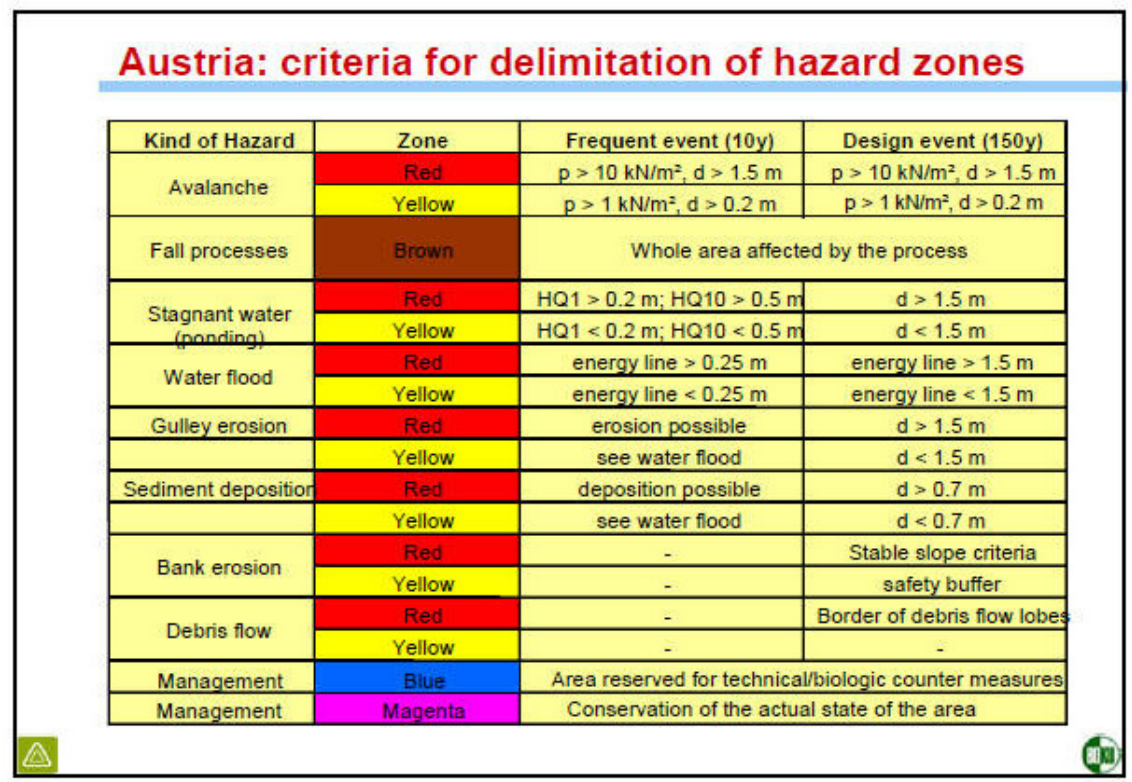

Figure 3: Delineations for the hazard zone mapping in Austria after Rickenmann [6].

\section{Damage, experiences and knowledge}

\subsection{Steel construction and damage on the discharge unit}

As mentioned before, in the year 2008 two events affected the technical protection measure during the construction work. The second one partly 


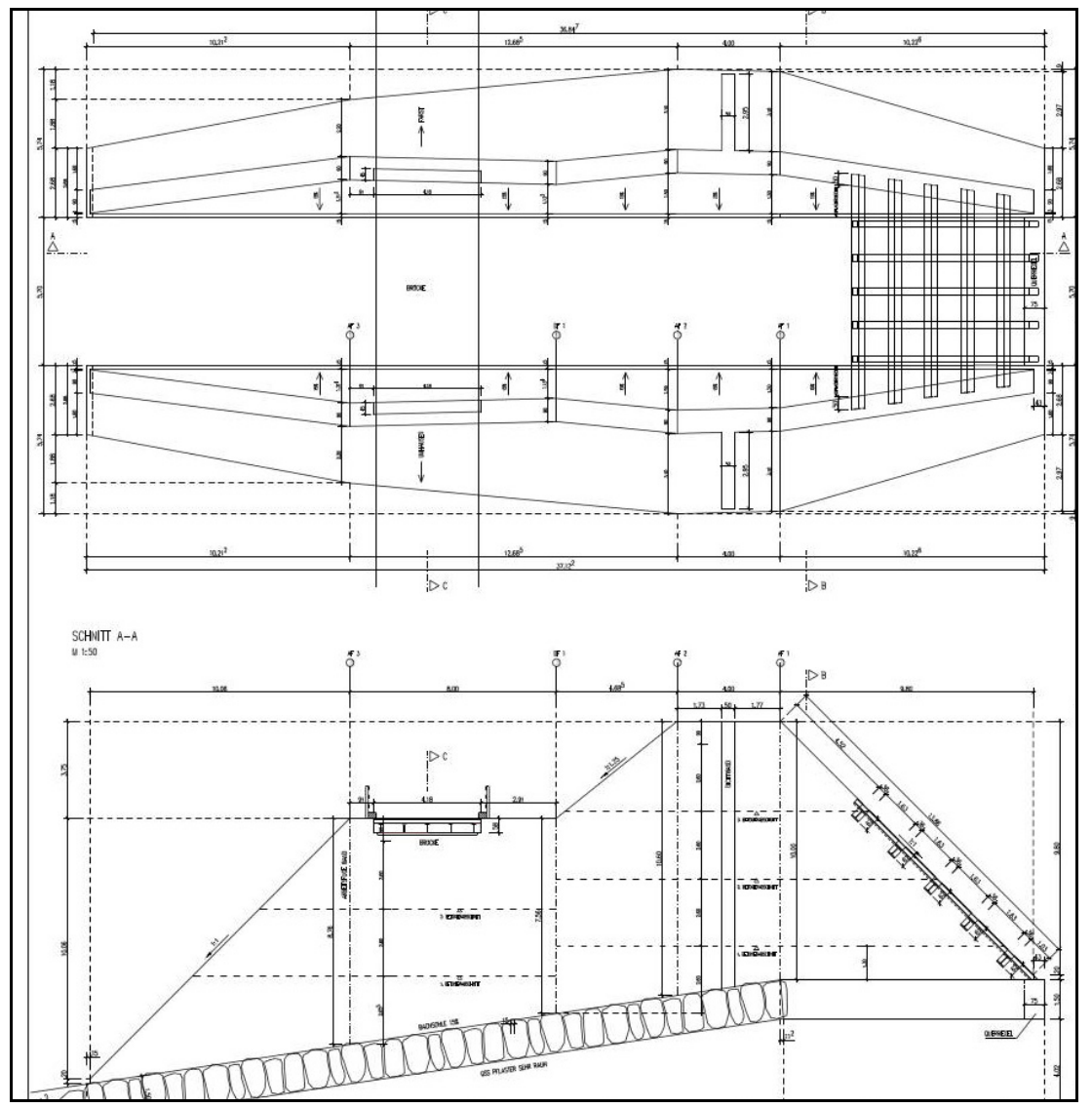

Figure 4: The angular steel girder of the upper discharge unit.

destroyed the discharge unit and completely damaged the angular steel girder, fig. 5. The major road into the Ötztal Valley was closed for two days but nevertheless no casualties were registered. This was the first time that such an event destroyed the steel girder that had been in normal use.

After this event the learning outcome was that the normally used dimensions for such steel girder on the basis of 1.5 times hydrostatic normal water pressure are not able to provide the occurring density and energy of a hyperconcentrated or of a debris flow. In this particular case, a large block crashed into the middle of the steel girder and an inflection of the steel occurred, fig. 5. This led to the collapse of the deposited material.

\subsection{Types of events in the year 2008}

In the year 2008 the smaller as well as the middle event were hyperconcentrated up to slurry flow after Selby [7]. The quantity of water was extremely high and the block sizes, which were transported in the medium, reached up to $7 \mathrm{~m}^{3}$ means 
132 Monitoring, Simulation, Prevention and Remediation of Dense and Debris Flows III

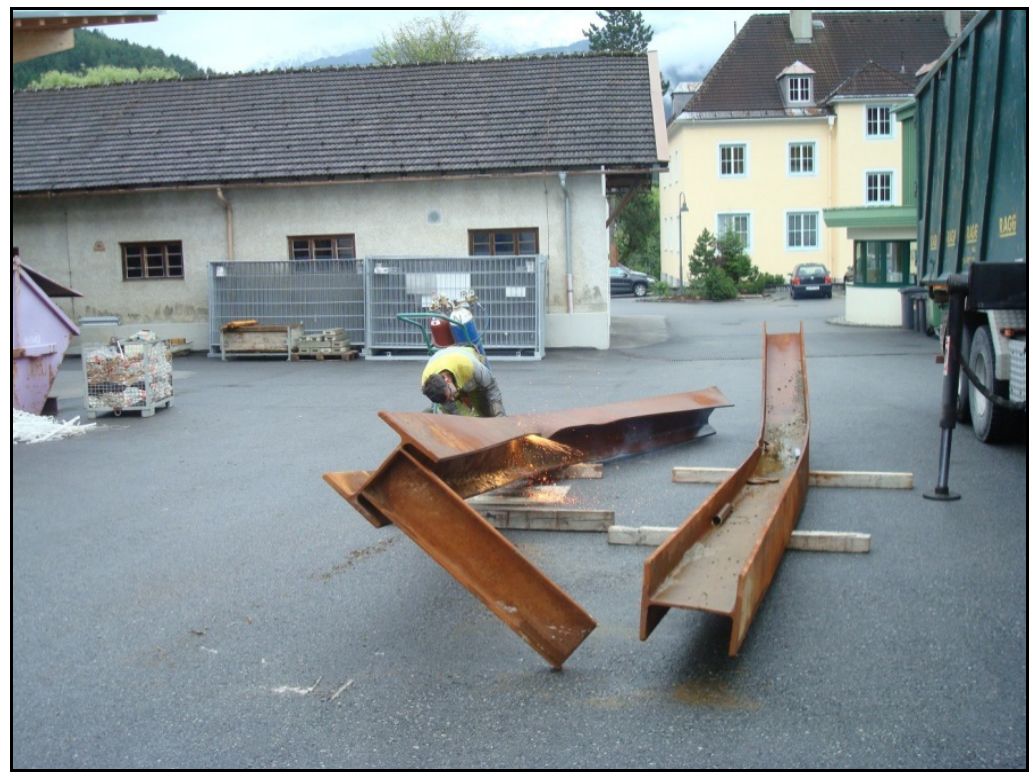

Figure 5: $\quad$ Deformation of the steel girder after the second event 2008.

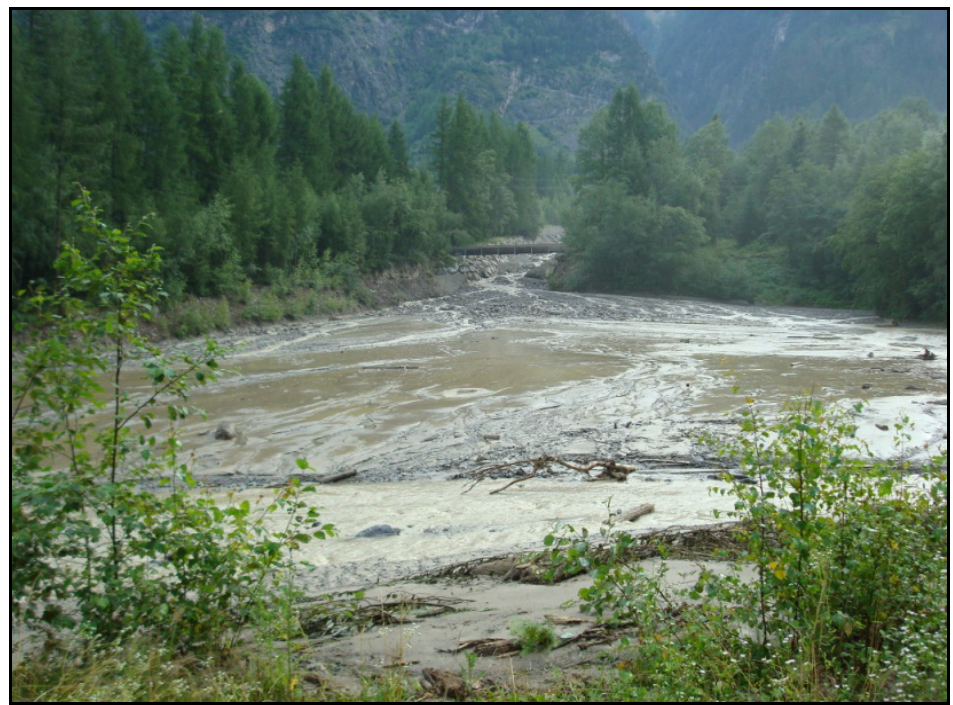

Figure 6: Hyperconcentrated up to slurry flow and deposition in the downstream basin after the second event 2008.

about 14 tonnes. In general, the events with a repeat period of time of 2-4 years are hyperconcentrated up to slurry flows. Only the large events, in comparison to 
the years 1749 or 1760 are typical debris flows and also the ancient debris cone indicates such former events.

\subsection{Conclusions}

Regarding the planning phase of such technical mitigation measures it is important to underline that natural disasters have a certain residual risk. Nevertheless, basic experiences which are gained during the period of time should inflow into further planning works. The main conclusion based on this illustration is that the 1.5 times hydrostatic normal water pressure is not sufficient enough to resist against hyperconcentrated or debris flows. The wingspan of the steel construction up to $6.0 \mathrm{~m}$ was also too extensive and smaller wingspans should be preferred.

Another point of view is the cost and height of the residual risk. If the residual risk is higher it is also possible to redevelop certain damages on the technical protection measures appearance during a flood event. Using a stronger steelprofile caused by a bigger dimension leads to enormously higher costs. Due to the higher costs of a stronger steel-profile, several redevelopments can also be undertaken. Therefore, the costs (monetary value) versus the benefits (residual risk) should be conscientiously regarded by the planners.

\section{Costs of the construction works undertaken on the torrent: "Farstrinne"}

The total costs of these technical protection measures are about 3.0 Mio $€$. The upper deposition basin costs 1.6 Mio $€$, the longitudinal dams costs 0.3 Mio $€$ and enlargement of the smaller basin downstream costs about 1.1 Mio $€$. As a requirement for the projects undertaken by the Austrian Federal Service for Torrent, Erosion and Avalanche Control, it is obligatory that in every project a cost/benefit analysis is done. This is the basis for the financial federal support. In the case of the "Farstrinne" the cost/benefit analysis represented a quotient of 1.4 for the benefit. It is not mandatorily necessary to reach a value above 1.0 but it is an important index and important for the decision-making process.

\section{References}

[1] Fliri, F., Naturchronik von Tirol: Tirol - Oberpinzgau - Vorarlberg Trentino, Beiträge zur Klimatographie von Tirol: Austria, 1998.

[2] Markart, G., Kohl, B., Sotier, B., Schauer, T., Bunza, G., Stern, R., Provisorische Geländeanleitung zur Abschätzung des Oberflächenabflussbeiwertes auf alpinen Boden-/Vegetationseinheiten bei konvektiven Starkregen, BFW-Praxisinformation 3/2004: Innsbruck, 2004.

[3] Ministry for Agriculture and Forestry (BMLFUW), Forestry Law 1975 , BGBl. Nr. 440/1975, idF BGBl. Nr. I108/2001: Austria, pp. 3-5, 43-45, 1975. 
134 Monitoring, Simulation, Prevention and Remediation of Dense and Debris Flows III

[4] Kohl, B., Stepanek, L., ZEMOKOST - neues Programm für die Abschätzung von Hochwasserabflüssen, BFW-Praxisinformation 8/2005: Innsbruck, pp.21-22, 2005.

[5] Rickenmann, D., Risk Analysis of Mountain Hazards, Lecture Notes of the University of Natural Resources and Applied Life Sciences in Vienna, part A Introduction: Vienna, pp. 29, 2006.

[6] Rickenmann, D., Hazard and Risk Assessment, Lecture Notes of the University of Natural Resources and Applied Life Sciences in Vienna, A1 Hazard Mapping part I (A): Vienna, 2006.

[7] Selby, M.J., Hillslope Materials and Processes, Oxford University Press: Oxford, pp. 299-304, 1993.

[8] http://www.die-wildbach.at/ 